\title{
The effect of intensity of the preexposed stimulus on subsequent conditioning
}

\author{
ALMA E. LANTZ \\ Denver Research Institute, University Park, Denver, Colorado 80210
}

\begin{abstract}
The intensity of a tone presented 60 trials prior to conditioning with a latent inhibition procedure in a conditional emotional response paradigm was either 60,90 , or $120 \mathrm{~dB}$. The tone either remained constant or was shifted between preexposure and conditioning. No effect of intensity was found when intensity remained constant, and a shift in intensity between 60 and $90 \mathrm{~dB}$ did not produce significant differences. A shift from a 60-dB tone during preexposure to a 120-dB tone in conditioning resulted in significantly better conditioning than a constant $60-\mathrm{dB}$ intensity tone. Implications of these results for "generalization" of a nonreinforced stimulus were discussed.
\end{abstract}

Latent inhibition is defined as a decrement in conditioned response performance following nonreinforced preexposure of the to-be-conditioned stimulus. The two phases of the latent inhibition paradigm are nonreinforced exposure to the stimulus, followed by conditioning to that stimulus. Nonreinforced exposure to a stimulus prior to its employment as a CS typically results in retarded acquisition. The retardation has been demonstrated with both human and infrahuman species in a variety of experimental situations (e.g., Lubow, 1973).

Lubow (1973) concluded that studies of latent inhibition showed unequivocally that the decremental effect on conditioning following stimulus preexposure is stimulus specific. That is, the inhibitory effect is limited only to that stimulus which has been preexposed. Certainly, the retardation in conditioning following preexposure does not occur when the stimuli are distinctly and qualitatively different. For example, no decrement in conditioning has been found when a click was used in one phase and a tone in the other (Carlton \& Vogel, 1967), or with a bell and a tone (Schnur \& Ksir, 1969), or a rotor and a light (Lubow \& Moore, 1959).

However, both habituating stimuli (nonreinforced exposure to stimuli) and conditioning stimuli have been shown to generalize. It would be expected, then, that some generalization might occur between the preexposed and conditioning stimuli. The occurrence of this generalization should reduce the attenuation of conditioning. For example, Siegel (1969) demonstrated that preexposed subjects evidenced the slowest acquisition of a conditioned eyeblink response to a CS of the same tonal frequency to which they were exposed prior to conditioning, with more rapid

The author wishes to thank Ms. Laurie West for technical assistance with this study. Requests for reprints should be sent to Alma E. Lantz, Denver Research Institute, Industrial Economics Division, University of Denver, Denver, Colorado 80210. Dr. Joseph Halpern sponsors this paper and takes full editorial responsibility for its content. conditioning to CS values further removed from the preexposed value.

Stimulus intensity effects have been observed in both conditioning and habituation paradigms. Lubow, Markman, and Allen (1968), using a latent inhibition procedure, found that conditioning increased as intensity increased, both for subjects who had stimulus preexposure, and those who did not. On the other hand, Crowell and Anderson (1972), also utilizing a CER paradigm, found no significant effect of shifting intensity of a tone between the preexposure and conditioning portions in a latent inhibition paradigm.

If an intense stimulus produces a stronger initial response (Davis \& Wagner, 1968) as well as better conditioning, some effect of shifting the intensity of the stimulus to a higher value between preexposure and conditioning should be obtained, i.e., the response decrement to a nonreinforced stimuli of lower intensity should occur more rapidly, but conditioning should be more effective with a higher intensity stimuli. The effect of a shift in the intensity of nonreinforced stimuli has been noted by Davis and Wagner (1968) and Groves and Thompson (1970).

The purpose of this research was to examine generalization when the preexposure stimuli and the conditioning stimuli varied in intensity in a CER paradigm, and the effect of direction of the intensity shift. The effect of intensity when the stimulus intensity was the same during preexposure and conditioning was also examined. In the latent inhibition CER situation, the effect of nonreinforced stimulation is assumed to be reflected in a greater attenuation of conditioning, resulting in less suppression in the presence of the stimulus after conditioning. A generalization decrement, then, would result in better conditioning after stimulus preexposure. Therefore, it was expected that groups receiving a shift in stimulus intensity between stimulus preexposure and conditioning should show better conditioning and more suppression because of 
the generalization decrement. Groups receiving higher intensity tone during preexposure, but conditioned to a less intense tone. should show less conditioning than groups receiving the less intense tone during preexposure and conditioned to a more intense tone.

\section{METHOD}

\section{Subject}

The subjects were 100 male albino rats obtained from Simonson Laboratories. All subjects were between 60 and 70 days old and weighed between 280 and $300 \mathrm{~g}$ at the beginning of the experiment.

\section{Apparatus}

All subjects were placed in a transparent Plexiglas chamber.with a grid floor; the chamber measured $21 \times 87 \times 14.5 \mathrm{~cm}$. The Plexiglas chamber was housed in a larger chamber made of plywood and lined with acoustical tile. The inside dimensions were $35 \times 35 \times 32 \mathrm{~cm}$. The chamber was illuminated by a $7-W$ white light. The auditory signal was a $1,000-\mathrm{Hz}$ tone, as calibrated by a Tektronix 545 oscilloscope. The tone was generated by an RCA model WA44C audio generator and was amplified by a Lafayette Model 1421 audio amplifier; it was delivered to the subjects through two 6.9- $\mathrm{cm}$ Archer 5-W 8-ohm conical speakers. The decibels of the tone were calibrated by a General Radio Model 1565A sound pressure level meter. The ambient noise level was approximately 20-32 dB SPC inside the chamber.

Shock could be delivered to the subjects through the grid floor of the chamber. The shock was generated by a Lafayette Model 5226 shocker at 500 ac shock voltage. with a $100 \mathrm{~K}$ external resistor, and was delivered via a Lafayette A620 grid scrambler. Control of the duration of the stimulus, the duration of the shock, and the interstimulus interval was provided by five Hunter timers. Response times were measured with a Hunter Model 1522 digital display timer counter. and a Lafayette Model 54015 digital stop clock; the drinkometer was a Grason-Stadler Model 4690A-1. All rats were maintained on ad-lib food and water except as noted below.

\section{Procedure}

There were 10 groups of 10 subjects each. Three stimulus intensities were employed: $60 \mathrm{~dB}, 90 \mathrm{~dB}$, and $120 \mathrm{~dB}$. Three groups served as nonpreexposed control groups, one at each of the decibel intensities. These groups remained in the experimental chamber for $40 \mathrm{~min}$ in the absence of auditory stimulation; following the $40-\mathrm{min}$ interval, each group received a single tone-shock pairing at one of the decibel levels. These three control groups were the $60-\mathrm{dB}$ group $(60 \mathrm{C})$, the $90-\mathrm{dB}$ group $(90 \mathrm{C})$, and the 120 -dB group (120C).

To test assumptions about intensity when measured under constant conditions, three groups (Group 60-60, Group 90-90, and Group 120-120) received $6010-\mathrm{sec}$ nonreinforced exposure to tones at a 30 -sec ISI at one of the three intensity levels followed by conditioning to the same tonal intensity.

To test assumptions about shifts in stimulus intensity, four groups received 60 nonreinforced 10 -sec tones at a 30 -sec ISI at one of the intensity levels, but were shifted during conditioning and testing to another intensity level. These were Group 60-90, Group 90-60, Group 120-60, and Group 60-120. The first value designates the decibel of the preexposed tone, and the second the decibel of the conditioning/testing tone.

All experimental subjects received 60 tones during the preexposure conditioning session. The 60th tone was paired with shock; $8 \mathrm{sec}$ after the onset of the tone, the shock came on for $2 \mathrm{sec}$ such that the offset of the tone and shock coincided. The control groups received the single tone-shock pairing in the same sequence. All subjects were returned to their home cages from which water had been removed.
Table 1

Mean Time to Complete 10 Licks in Seconds After Onset of the Tone

\begin{tabular}{|c|c|c|c|c|c|c|}
\hline $\begin{array}{c}\text { Condition- } \\
\text { ing/Test }\end{array}$ & Group & $\begin{array}{c}\text { Intensity } \\
60 \mathrm{~dB}\end{array}$ & Group & $\begin{array}{c}\text { Intensity } \\
90 \mathrm{~dB}\end{array}$ & Group & $\begin{array}{c}\text { Intensity } \\
120 \mathrm{~dB}\end{array}$ \\
\hline $\begin{array}{l}\text { Control } \\
\text { Constant } \\
\text { Shifted }\end{array}$ & $\begin{array}{r}0-60 \\
60-60 \\
90-60\end{array}$ & $\begin{array}{r}221.10 \\
1.42 \\
6.07\end{array}$ & $\begin{array}{r}0-90 \\
90-90 \\
60-90\end{array}$ & $\begin{array}{r}200.80 \\
1.46 \\
4.43\end{array}$ & $\begin{array}{r}0-120 \\
120-120 \\
60-120\end{array}$ & $\begin{array}{r}254.70 \\
4.70 \\
45.40\end{array}$ \\
\hline & $120-60$ & 1.08 & & & & \\
\hline
\end{tabular}

The testing session was given $24 \mathrm{~h}$ later. Each subject was placed in a chamber identical to that used in the preexposure/conditioning session except that a drinking tube was now present. After the subject had completed 100 licks, the tone. identical to that used during conditioning, was initiated. The time from the onset of the tone until the completion of 10 licks was used as a response measure to indicate the amount of suppression occasioned by the tone. All subjects were removed from the experimental chamber if they had not completed 10 licks within $600 \mathrm{sec}$ after the onset of the tone, and their response time was recorded as $600 \mathrm{sec}$.

\section{RESULTS}

Table 1 gives the mean suppression, or the time to complete the initial 10 licks after the onset of the tone in the testing session, and the standard deviation of the mean for all preexposed groups, preexposed/ shifted groups, and nonpreexposed control groups. A comparison by a Mann-Whitney $U$ of the means of preexposed and nonpreexposed control treatments was significant at each intensity level. That is, the nonpreexposed control and the preexposed groups were significantly different at $60 \mathrm{~dB} \quad(\mathrm{U}=0$, $\mathrm{p}<.05)$, at $90 \mathrm{~dB}(\mathrm{U}=3, \mathrm{p}<.05)$, and at $120 \mathrm{~dB}$ $(\mathrm{U}=1, \mathrm{p}<.05)$. These differences again demonstrate the strong effect of attenuation of conditioning following stimulus habituation.

A Kruskal-Wallis one-way analysis of variance showed no significant differences among the $60-\mathrm{dB}$, the $90-\mathrm{dB}$, and the $120-\mathrm{dB}$ nonpreexposed control groups, as well as no difference among the constant intensity groups preexposed and conditioned to either $60 \mathrm{~dB}, 90 \mathrm{~dB}$, or $120 \mathrm{~dB}$. That is, no effect of intensity was found when the intensity of the tone was the same in preexposure and conditioning.

No significant effect, with a Mann-Whitney U, was found between three of the groups experiencing a shift in intensity between habituation and conditioning (Groups 60-90, 90-60, and 120-60) when the groups were compared to preexposed groups receiving the same conditioning intensity, i.e., Group 90-90 and Group 60-60. A significant effect of shifting intensities was found with Group 60-120 $(U=16$, $\mathrm{p}<.05$ ), when it was compared to Group 120-120.

\section{DISCUSSION}

The conditioning of the preexposed groups receiving constant levels of stimulus intensity were very similar, regardless of the 
intensity level. These data, then, do not confirm the effects of increasing stimulus intensity in increasing conditioning in latent inhibition found by Lubow, Markman, and Allen (1968). The present experiment did, however, find the same constant difference between the preexposed and control groups, regardless of intensity, obtained in the Lubow et al. experiment.

A failure to find differences in conditioning when the two intensities were different would indicate generalization between the preexposure CS and the conditioning CS. Thus, generalization was found for groups receiving the smaller difference between stimulus intensities (.30 dB). This confirmed the Crowell et al. (1972) finding with a similar paradigm of generalization at approximately the same range and intensity values.

A generalization decrement was obtained for Group 60-120 when it was compared to Group $120-120$, i.e., Group $60-120$ demonstrated significantly better conditioning and more suppression. Since Group 120-60, which experienced the same absolute difference in intensity between preexposure and conditioning. was not significantly different from Group $60-60$, it is likely that the generalization decrement was a function of the direction of the shift. In other words. the enhanced conditioning resulted. not from the absolute difference between the two intensities. but from the directionality of the difference.

This is the first demonstration of a generalization decrement in a latent inhibition procedure resulting from shifting intensity of the stimulus between preexposure and conditioning, although it had been noted with stimulus frequency (Siegel. 1969). However, the lack of complete generalization between the preexposed and conditioning stimuli was only noted when the difference between intensities was great. and when the intensity of the conditioning stimuli was greater than the preexposure stimuli. In sum. then, generalization decrements do occur in the latent inhibition paradigms. although either large stimulus differences or more sensitive procedures must be utilized to show them.

Even though the results are inconclusive because an "explicitly unpaired" control group was not run, the results are most easily explained by some form of a stimulus effectiveness or attentional theory, such as the one proposed by Carlton and Vogel (1967). That is, more attention would be elicited by an increase in stimulus intensity following preexposure than would be elicited by either a constant or decreased value.

\section{REFERENCES}

Carlton, P. L., \& Vogel, J. R. Habituation and conditioning. Journal of Comparative and Physiological Psychology, 1967, 63, 348-351.

Crowell, C. R., \& Anderson, D. C. Variations in intensity, interstimulus interval and interval between preconditioning CS exposures and conditioning with rats. Journal of Comparative and Physiological Psychology, 1972, 79, 291-298.

DA vis, M., \& WAgner, A. R. Startle responsiveness after habituation to different intensities of tone. Psychonomic Science, 1968, 12, 337-338.

Groves, P. M., \& Thompson, R. F. Habituation: A dual process theory. Psychological Review, 1970, 77, 419-450.

Lubow, R. E., \& Moore, A. E. Latent inhibition: The effect of nonreinforced preexposure to the conditioned stimulus. Journal of Comparative and Physiological Psychology, 1959, 68, 136-138.

Lubow, R. E., Markman, R. E., \& Allen, J. Latent inhibition and classical conditioning of the rabbit pinna response. Journal of Comparative and Physiological Psychology, 1968, 66. 688-694.

LuBow, R. E. Latent inhibition. Psychological Bulletin, 1973, 79, 398-407.

SChNuR, P., \& KsIR, C. J. Latent inhibition in human eyelid conditioning. Journal of Experimental Psychology, 1969. 80, 388-389.

SIEGEL, S. Generalization of latent inhibition. Journal of Comparative and Physiological Psychology, 1969, 69, 157-159.

(Received for publication January 18, 1976.) 